\title{
State and Local Projects, Risk Assessment and Prevention
}

National Cancer Institute

\section{Source}

National Cancer Institute. State and Local Projects, Risk Assessment and Prevention. NCI Thesaurus. Code C19042.

2C4b; Risk Assessment and Prevention; Information And Education/Preventive Services; General Public And Special Programs; Regional, state, and local 